\title{
Cyclopentenyl cytosine has biological and anti-tumour activity, but does not enhance the efficacy of gemcitabine and radiation in two animal tumour models
}

\author{
CHRIS VAN BREE ${ }^{1}$, ANGELIQUÉ D. BARTEN-VAN RIJBROEK ${ }^{3}$, RENÉ LEEN $^{2}$, \\ HANS M. RODERMOND ${ }^{1}$, ANDRÉ B.P. VAN KUILENBURG ${ }^{2}$ and HENK B. KAL ${ }^{3}$ \\ Departments of ${ }^{1}$ Radiation Oncology, Laboratory for Experimental Oncology and Radiobiology, and \\ ${ }^{2}$ Genetic and Metabolic Diseases, Academic Medical Centre-University of Amsterdam, P.O. Box 22700, \\ 1100 DE Amsterdam; ${ }^{3}$ Department of Radiotherapy, Q 00.118. University Medical Center Utrecht, \\ Heidelberglaan 100, 3584 CX Utrecht, The Netherlands
}

Received September 24, 2008; Accepted November 28, 2008

DOI: 10.3892/ijo_00000207

\begin{abstract}
Cyclopentenyl cytosine (CPEC), targetting the de novo biosynthesis of cytidine triphosphate (CTP), increases the cytotoxicity of gemcitabine (2',2'-difluoro-2'-deoxycytidine, $\mathrm{dFdC}$ ) alone and in combination with irradiation in several human tumour cells in vitro. We investigated whether CPEC enhances the therapeutic ratio of gemcitabine and irradiation in human pancreatic BxPC-3 xenografts and in rat syngeneic L44 lung tumours. These models were selected because gemcitabine and radiation are used to treat both pancreatic and lung cancer patients and both models differ in growth capacity and in gemcitabine-induced radiosensitisation. A profound dose-dependent CTP-depletion was observed after a single injection of CPEC in both tumour tissue and in normal jejunum. In both models, CPEC alone induced a slight but significant tumour growth delay. The combination of CPEC with gemcitabine, at time intervals that showed CTP-depletion after CPEC, enhanced neither tumour growth delay nor toxicity as compared to gemcitabine alone. In addition, no beneficial effect of CPEC was observed in combination with gemcitabine and radiation. These results suggest that CPEC and gemcitabine alone as well as in combination with radiation target a similar cell population in both tumour models. In conclusion, future clinical development of CPEC as a modulator of gemcitabine combined with radiation is unlikely.
\end{abstract}

Correspondence to: Dr Henk B. Kal, Department of Radiotherapy, Q 00.118, University Medical Center Utrecht, Heidelberglaan 100, 3584 CX Utrecht, The Netherlands

E-mail: h.b.kal@umcutrecht.nl

Key words: cyclopentenyl cytosine, gemcitabine, ionising radiation, pancreatic cancer, L44 lung tumour, BxPC-3 pancreatic tumour

\section{Introduction}

Despite the progress in diagnostic tools, approximately half of all patients suffering from pancreatic cancer presents with locally advanced disease with a very poor prognosis (1). Currently, gemcitabine $\left(\right.$ Gemzar $^{\circledR}, 2^{\prime}$, 2'-difluoro-2'-deoxycytidine, $\mathrm{dFdC}$ ) is the standard treatment for these patients, but with only marginal clinical benefit (2). Since gemcitabine enhances the radiosensitivity of tumour cells in vitro and in vivo (3-10), several phase I and II studies have investigated concurrent gemcitabine and radiotherapy. Unfortunately, acute gastrointestinal toxicity was encountered with standard doses of gemcitabine and radiotherapy, which depended on the irradiated volume (11-14). Also in patients with nonsmall cell lung cancer (NSCLC) caution needs to be used, when gemcitabine and radiotherapy are applied concurrently (15). Reduction of the dose of gemcitabine, radiation or the radiation volume appears to facilitate concurrent chemoradiotherapy, but this may reduce the anti-tumour effectiveness.

Recently, we showed that targeting the de novo pathway for the synthesis of cytidine triphosphate (CTP) by cyclopentenyl cytosine (CPEC, NSC 375575) in human pancreatic carcinoma and NSCLC cell lines not only increased the anabolism and the cytotoxicity of gemcitabine, but also increased the radiosensitisation of gemcitabine (16). CPEC is a cytidine analogue, which depletes both cytidine pools and deoxycytidine pools by inhibiting CTP synthetase (17-19). Because the activity of CTP synthetase has been shown to be elevated in solid tumours (20) and CPEC has been suggested to selectively target tumour cells in vivo (21), CPEC could potentially increase the therapeutic ratio of gemcitabine and radiation. To test this hypothesis, we used the human pancreatic BxPC-3 xenograft model, in which gemcitabine combined with radiation has limited efficacy (9), and the rat lung L44 tumour model, in which gemcitabine significantly enhanced radiation effectiveness (10). In this report, we show that CPEC reduces CTP-levels selectively in tumour tissue and is effective in 
slowing down tumour growth. However, the effectiveness of gemcitabine either alone or in combination with radiation was not enhanced by CPEC in both tumour models.

\section{Materials and methods}

Drugs and chemicals. RPMI with HEPES, PSG (100* stock of $10000 \mathrm{U} / \mathrm{ml}$ penicillin, $10 \mathrm{mg} / \mathrm{ml}$ streptomycin and $20 \mathrm{mmol} / \mathrm{l}$ glutamine) were purchased from Gibco-BRL (Paisley, UK), gemcitabine from Eli Lilly (Nieuwegein, The Netherlands). CPEC (NSC 375575) was obtained from the Developmental Therapeutics Program, National Cancer Institute (Bethesda, MD, USA). All nucleotide standards were obtained from Sigma Chemicals (Zwijndrecht, The Netherlands). All other chemicals were of analytical grade and commercially available.

Tumour models. The L44 is a radiation-induced anaplastic tumour, originally diagnosed as an adenosquamous lung carcinoma, which grows in the Brown Norway rat [BN(Orl)Ico, Charles River, Maastricht, The Netherlands] with a tumour volume doubling time of about 4 days $(22,23)$. Female BN rats were inoculated in the flank with tumour pieces of about $2 \mathrm{~mm}^{3}$. L44 tumours were treated at a volume between 500 and $1000 \mathrm{~mm}^{3}$ (mean \pm SE: $632 \pm 36 \mathrm{~mm}^{3}$ ).

The BxPC-3 is a moderately well to poorly differentiated pancreatic carcinoma, originally derived from a 61-year old female (24), which grows in athymic nude mice with a tumour doubling time of about 10 days. The human pancreatic cell line BxPC-3 (American Type Culture Collection, Manassas, VA, USA) was grown as a monolayer in RPMI with HEPES supplemented with $10 \%$ heat-inactivated fetal bovine serum (FBS) and PSG at $37^{\circ} \mathrm{C}$ at $5 \% \mathrm{CO}_{2}$. BxPC-3 cells were passaged twice weekly to ensure exponential growth. Female nu/nu mice (6-8 weeks old, Harlan Sprague-Dawley, Horst, The Netherlands) were subcutaneously injected with $10^{7}$ BxPC-3 cells mixed (1:2) with Matrigel (BD Biosciences, Erembodegem, Belgium). BxPC-3 tumours were treated at a volume between 200 and $500 \mathrm{~mm}^{3}$ (mean \pm SE: $353 \pm 24 \mathrm{~mm}^{3}$ ). All animal experiments were approved by the animal ethics committee of the University Medical Center Utrecht (L44 model) and of the Academic Medical Center in Amsterdam (BxPC-3 model).

Chemotherapeutic treatments. CPEC was administered by an i.p. injection of various doses based on earlier results of mice and rat studies $(21,25)$. A pilot experiment in $\mathrm{BN}$ rats without tumours was performed to show that CPEC up to a dose of $90 \mathrm{mg} / \mathrm{kg}$ did not result in any toxicity for at least 3 months after treatment. Lack of toxicity of CPEC alone in rats is in agreement with data showing no toxicity after an i.v. bolus of $20 \mathrm{mg} / \mathrm{kg}$ (26) or after i.p. treatment with doses up to $90 \mathrm{mg} / \mathrm{kg}$ (25). Treatment with CPEC was considered $\mathrm{t}=0 \mathrm{~h}$ throughout this study.

Gemcitabine was administered at various time intervals after treatment with CPEC by an i.p. injection of 120 or $240 \mathrm{mg} / \mathrm{kg}$ once a week for two consecutive weeks in the BxPC-3 model $(6,9)$ and of a single i.p. injection of $30 \mathrm{mg} / \mathrm{kg}$ in the L44 model (10).
Radiation treatments. Irradiation was applied in both models $24 \mathrm{~h}$ after treatment with gemcitabine because of the reported largest therapeutic benefit in animal models $(6,9,10)$. For the L44 model, X-ray doses of $10 \mathrm{~Gy}(200 \mathrm{kVp}, 20 \mathrm{~mA}$, $0.5 \mathrm{~mm} \mathrm{Cu}$, dose rate $4 \mathrm{~Gy} / \mathrm{min}$; Philips Orthovolt RT250) were administered locally under hypnorm/dormicum anesthesia.

For the BxPC-3 model, animals received a dose of $3 \mathrm{~Gy}$ once a week for two consecutive weeks by whole-body irradiation using a ${ }^{137} \mathrm{Cs}$-source (Cis Bio International IBL637, Gif-sur-Yvette, France) at a dose rate of $\sim 1$ Gy per minute without anesthesia. A pilot experiment in nude mice without tumours was performed to show that this treatment did not result in any toxicity for at least 3 months after treatment.

In vivo end-points. Tumours were measured 1-2x per week with Vernier calliper and tumour volume was calculated as based on two orthogonal cross-sectional diameter measurements ( $\mathrm{V}=0.5 a^{2} b$, with a the smallest diameter). Toxicity was evaluated 1-2x per week by body-weight measurements and the general physical condition of the animals.

At several time intervals after administration of CPEC, the proximal part of the jejunum $(\sim 3 \mathrm{~cm})$ and tumour tissue were isolated and within $1 \mathrm{~min}$ snap-frozen in liquid nitrogen and stored for nucleotide analysis at $-80^{\circ} \mathrm{C}$. The tissue was grinded in liquid nitrogen using a morter and after evaporation of the nitrogen the tissue was quickly extracted with $200 \mu 1$ of ice-cold $0.4 \mathrm{M}$ perchloric acid for $10 \mathrm{~min}$ on ice. The resulting suspension was centrifuged at $10,000 \mathrm{~g}$ at $4^{\circ} \mathrm{C}$ for 5 min. Supernatant was removed, neutralised with $\mathrm{K}_{2} \mathrm{CO}_{3}$ and used for HPLC analysis. Nucleotide profiles were determined by ion-exchange HPLC, using a Whatman (Clifton, NJ) Partisphere SAX 4.6x125 mm column (5- $\mu$ m particles) and a Whatman 10x2.5 mm AX guard column (27).

\section{Results}

Biological activity of CPEC. To verify that CPEC was targeting CTP synthetase in our tumour models, the CTP/UTP ratios were analysed in both tumour tissue and jejunum (as the normal tissue at risk for chemoradiotherapy for pancreatic tumours) at several time-points after a single treatment with different doses of CPEC. In the subcutaneous human pancreatic BxPC-3 xenograft model in nude mice, the i.p. administration of CPEC was able to significantly reduce CTP/UTP-levels in tumours at a dose of $3 \mathrm{mg} / \mathrm{kg}$ (Fig. 1A). A higher dose of $10 \mathrm{mg} / \mathrm{kg}$ resulted in a slightly increased effect, but the kinetics were quite similar with a decrease in CTP/UTP ratios lasting for at least $48 \mathrm{~h}$. Comparing the CTP/UTP levels in tumour tissue with those in jejunum showed that only at $48 \mathrm{~h}$ after $3 \mathrm{mg} / \mathrm{kg}$ CPEC there was a significant selective targeting of CTP/UTP levels in tumour tissue (Fig. 1B). For treatment with $10 \mathrm{mg} / \mathrm{kg}$ however, we found a selective targeting in tumour tissue from 16 to $48 \mathrm{~h}$ after treatment. Subsequently, we found that CPEC was also able to transiently decrease $\mathrm{CTP} / \mathrm{UTP}$ levels in the subcutaneous rat L44 tumour model (Fig. 1C).

Anti-tumour activity of CPEC. Next, the anti-tumour effects of CPEC alone in doses that were able to decrease CTP/UTP 

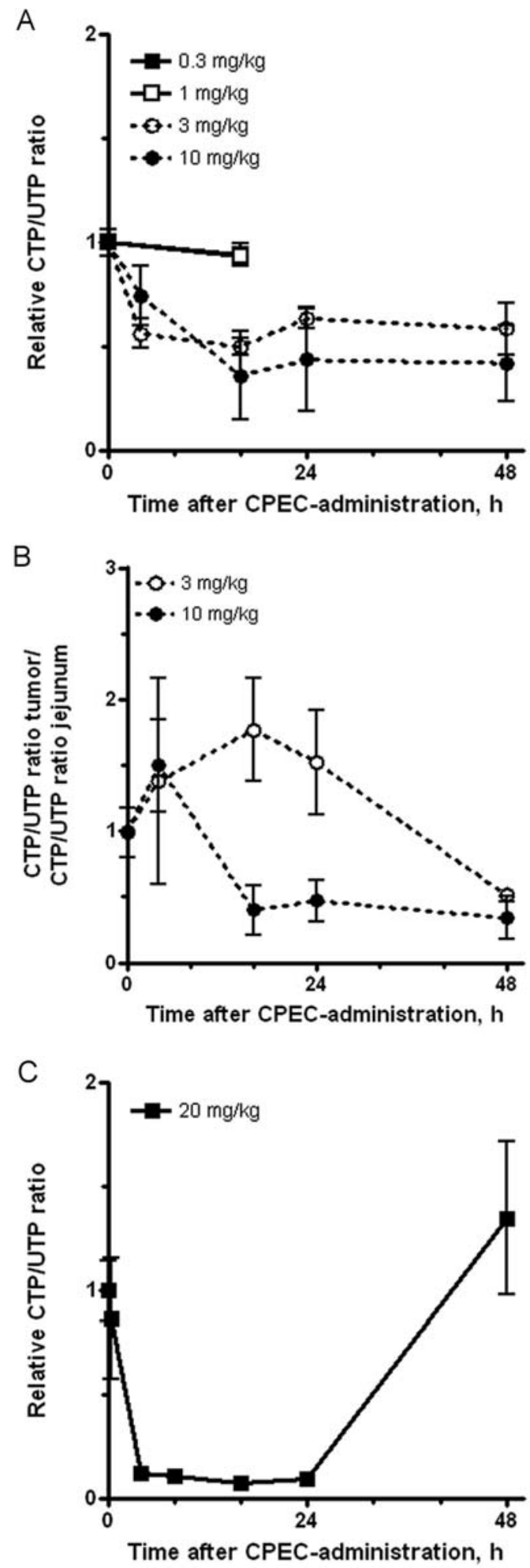

Figure 1. Kinetics of CTP-levels in tissue after a single treatment with CPEC. The CTP/UTP ratio as compared to untreated control animals in tumour tissue of human pancreatic BxPC-3 xenografts in nude mice (A) and rat lung L44 (C) is plotted against time after CPEC-administration with indicated doses. The ratio of $\mathrm{CTP} / \mathrm{UTP}$-levels of tumour tissue and jejunum after CPEC-administration is shown for human BxPC-3 xenografts in nude mice (B). A ratio below 1 indicates tumour selective CTP-depletion. Means with standard errors are shown of at least three animals in two separate experiments.

ratios in the human pancreatic $\mathrm{BxPC}-3$ xenografts were investigated (Fig. 2A). Treatment with either 3 or $10 \mathrm{mg} / \mathrm{kg}$
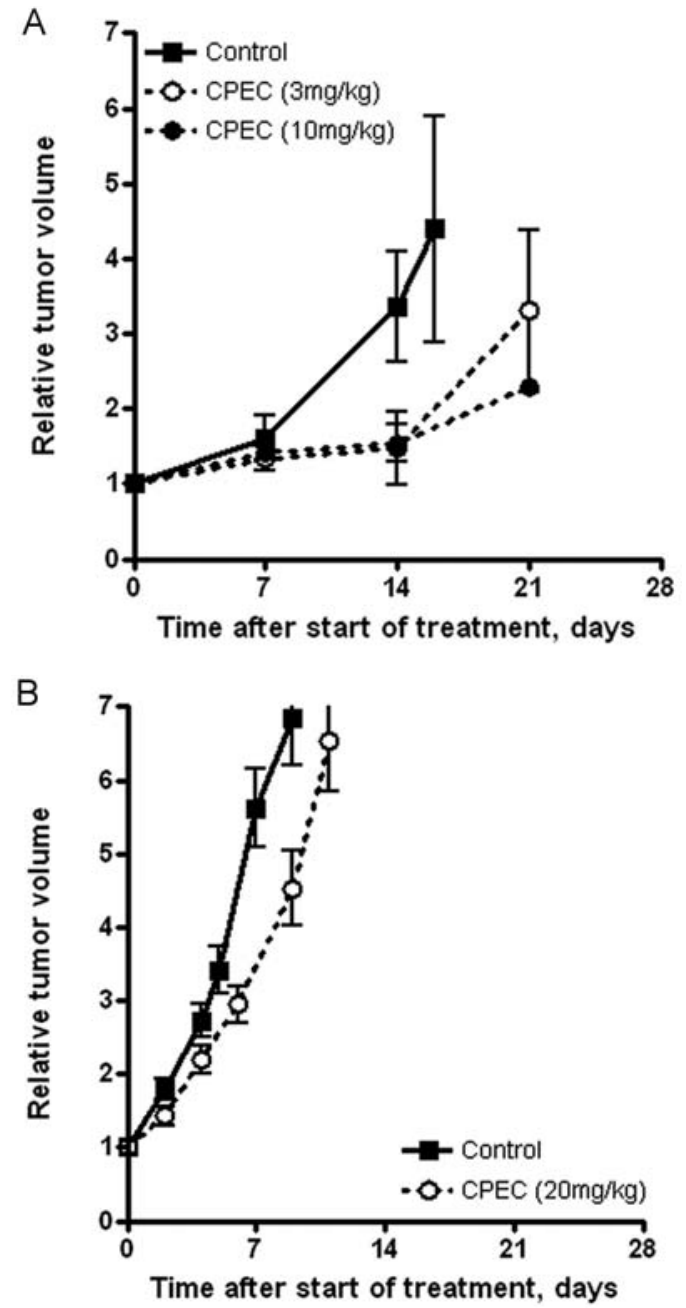

C

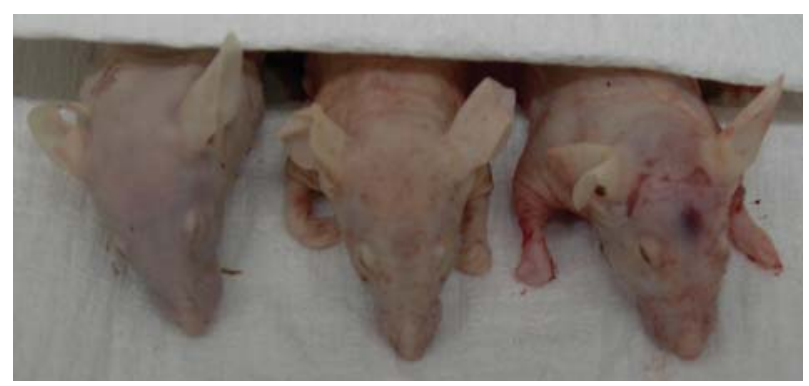

Figure 2. CPEC reduces growth of human pancreatic BxPC-3 xenografts in nude mice (A) and rat lung L44 tumours (B). The tumour volume as compared to the start of treatment is plotted against time after treatment with CPEC at indicated doses. Means with standard errors are shown of at least three animals. Examples of subcutaneous bleedings in two nude mice (middle and right) treated with $10 \mathrm{mg} / \mathrm{kg} \mathrm{CPEC} \mathrm{at} 48 \mathrm{~h}$ after administration (C). An untreated animal (left) is shown for comparison.

resulted in a similar tumour growth delay of $\sim 7$ days in the BxPC-3 xenograft. A dose of $20 \mathrm{mg} / \mathrm{kg}$ CPEC caused a growth delay of 3 days in the L44 tumour (Fig. 2B). With respect to toxicity of CPEC-treatment we noted that in about half of the nude mice treated with $10 \mathrm{mg} / \mathrm{kg}$ CPEC small, subcutaneous bleedings occurred (Fig. 2C). The bleeding always recovered within 1 week after CPEC administration and were not accompanied by significant weight loss or other types of toxicity. In the $\mathrm{BN}$ rats, subcutaneous bleeding was 

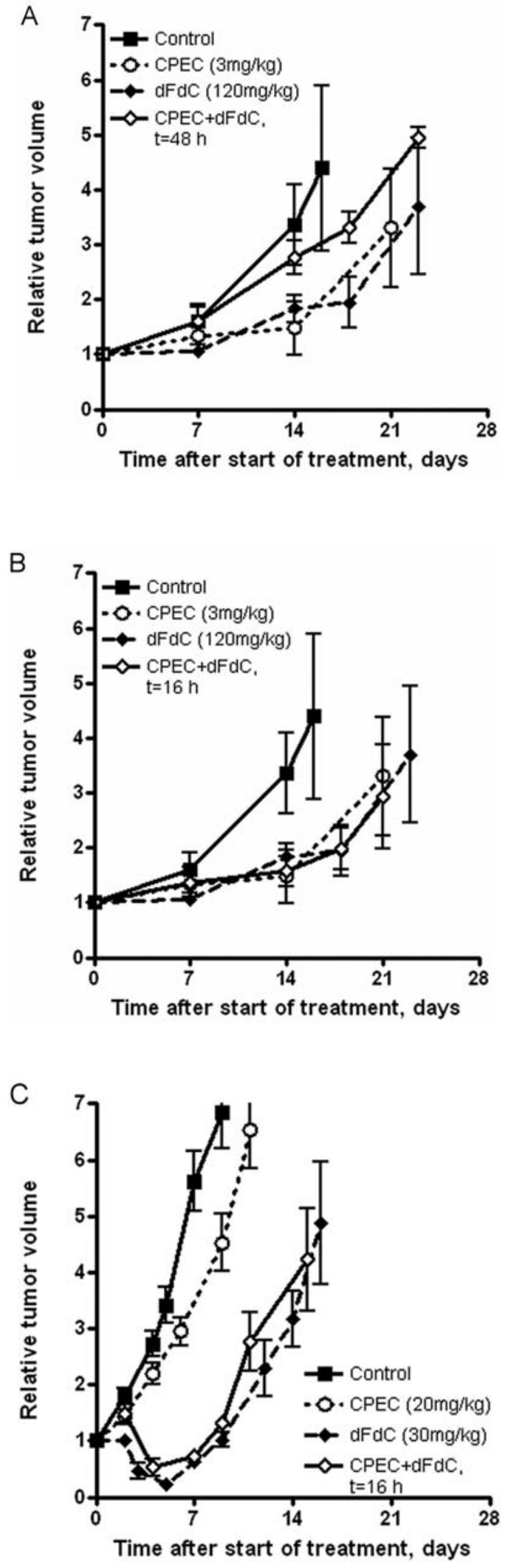

Figure 3. CPEC does not enhance the effectiveness of $\mathrm{dFdC}$ in human pancreatic BxPC-3 xenografts in nude mice (A and B) and rat lung L44 tumours $(\mathrm{C})$. The tumour volume as compared to the start of treatment is plotted against time after treatment with CPEC and gemcitabine $(\mathrm{dFdC})$ at indicated doses. Treatment with $\mathrm{dFdC}$ was performed at $48 \mathrm{~h}(\mathrm{~A})$ or $16 \mathrm{~h}$ (B and C) after CPEC-administration. Means with standard errors are shown of at least three animals.
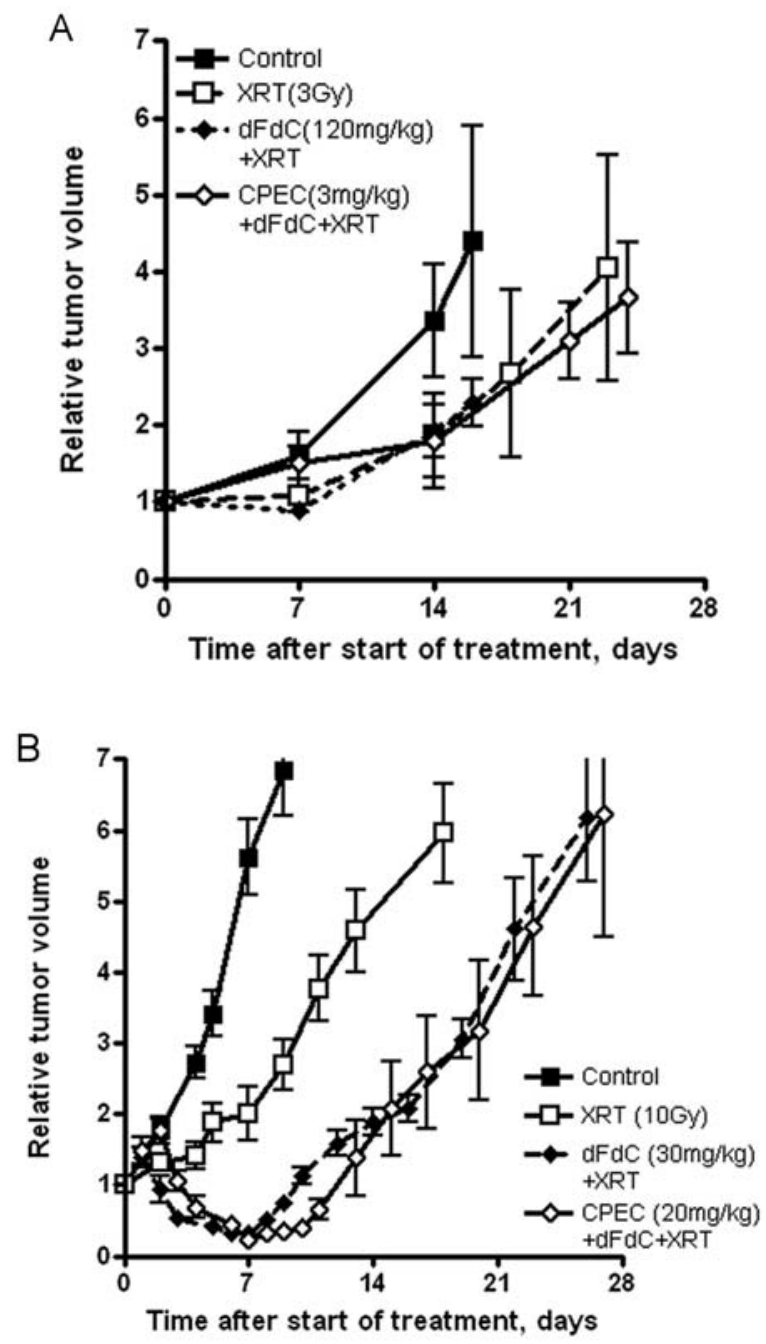

Figure 4. CPEC does not enhance the effectiveness of $\mathrm{dFdC}$ in combination with radiation (XRT) in human pancreatic BxPC-3 xenografts in nude mice (A) and in rat lung L44 tumours (B). The tumour volume as compared to the start of treatment is plotted against time after treatment with CPEC, gemcitabine $(\mathrm{dFdC}$, at $\mathrm{t}=16 \mathrm{~h}$ after $\mathrm{CPEC})$ and XRT at indicated doses. Tumour growth curves of CPEC alone, dFdC alone, CPEC+dFdC and $\mathrm{CPEC}+\mathrm{XRT}$ are similar to XRT alone and are not shown for clarity. Means with standard errors are shown of at least three animals.

not observed, even when doses up to $90 \mathrm{mg} / \mathrm{kg}$ were used. No significant reduction of body weight was encountered after treatment with CPEC in both animal strains.

Anti-tumour activity of combined treatments. Based on our observation that CPEC ( $3 \mathrm{mg} / \mathrm{kg})$ selectively targeted CTP/UTP levels at $48 \mathrm{~h}$ after treatment (Fig. 1B), we first combined this dose of CPEC with $\mathrm{dFdC}$ at this time-point. Disappointingly, no differences were observed as compared to treatment with $\mathrm{dFdC}$ alone (Fig. 3A). In addition, no significant increase in tumour growth delay was observed in the BxPC-3 model when $\mathrm{dFdC}$ was administrated $16 \mathrm{~h}$ after the treatment with CPEC (Fig. 3B). At this time interval, an optimal reduction in CTP/UTP ratios in tumour tissue was present (Fig. 1). Because the interaction between CPEC and $\mathrm{dFdC}$ depended on the dose of both drugs in vitro (16), we 
tested different doses of both CPEC and $\mathrm{dFdC}$ in the BxPC3 model, but tumour growth delay of combined treatments were not significantly larger than for $\mathrm{dFdC}$ alone (data not shown). Also in the L44 tumour model, CPEC (20 mg/kg) did not enhance the effectiveness of $\mathrm{dFdC}$ alone (Fig. 3C).

Finally, CPEC was combined at several time intervals with $\mathrm{dFdC}$ and irradiation schedules, which have been reported for human pancreatic BxPC-3 xenografts (9) and for rat lung L44 tumours (10). The addition of CPEC to the combination of $\mathrm{dFdC}$ and radiation did not result in a significantly larger effect on tumour growth delay in either tumour model (Fig. 4).

\section{Discussion}

Since its discovery as an anti-tumour agent, CPEC has shown activity in leukemia, glioblastoma, neuroblastoma, colon carcinoma, non-small cell lung carcinoma and pancreatic carcinoma $(16,18,21,27-29)$. The target of the triphosphate form of CPEC is CTP synthetase, which catalyses the conversion of UTP into CTP. A decrease in CTP/UTP levels has therefore been used to demonstrate biological activity both in cell culture (16-19) and in patients samples $(30,31)$. CPEC already entered phase-I clinical testing as a single treatment modality. This trial included 26 patients with various solid tumours, but was prematurely stopped because of fatal hypotension in two patients (30). However, direct cardiotoxicity was not observed when CPEC was given to rats in doses up to $90 \mathrm{mg} / \mathrm{kg}$ (25), leaving the fatal hypotension encountered in patients unexplained. It has become evident that CPEC as a single anti-tumour agent has only limited efficacy $(30,32,33)$. Since CPEC was able to inhibit the activity of CTP synthetase in bone marrow mononuclear cells of patients treated with CPEC doses that did not induce hypotension (30), it was suggested to use CPEC as a biochemical modulator of other chemotherapeutic drugs, such as cytarabine (Ara-C) and gemcitabine.

CPEC indeed enhanced the anabolism and cytotoxicity of cytarabine and gemcitabine have been shown for various human tumour cell lines $(16,18,19,27,34-36)$. To our knowledge there is only one report on the interaction between CPEC and cytarabine or gemcitabine in vivo. CPEC was combined with a palmitate derivative of cytarabine in a murine L1210 leukemia model (37). CPEC at non-toxic doses $(<2.5 \mathrm{mg} / \mathrm{kg}$ : two i.p. doses with a 6-h interval on days 4 and 8 after inoculation) increased the effects of lower doses of cytarabine, while higher dose combinations were toxic. No additional in vivo studies on the combination of CPEC with cytarabine or gemcitabine have been published, although the applicability of modulating the de novo biosynthesis of nucleotides to enhance the effectiveness of gemcitabine has been shown in vivo (38). In a nude mouse xenograft model of human pancreatic carcinoma Miapaca- 2 cells, repeated administration of siRNA against ribonucleotide reductase enhanced the anti-tumour effect of gemcitabine without increasing toxicity, while the number of liver metastases was reduced. To study the efficacy of CPEC combined with gemcitabine and radiation we used a human pancreas xenograft model and a rat lung tumour model, in which gemcitabine alone as well as gemcitabine in combination with radiation have been described $(9,10)$. These models are clinically relevant, because gemcitabine is used for the treatment of patients with both pancreatic and non-small cell lung cancer. Moreover, gemcitabine is used in combination with radiotherapy albeit with a small therapeutic ratio (11-15).

Our data clearly show that CPEC is biologically active because it transiently depletes CTP levels both in tumour tissue and in the jejunum, which is the critical normal tissue for chemo-radiation treatment of locally advanced pancreatic cancer (11-14). We also show prolonged and tumour-selective depletion of CTP levels that would allow for an increase in the therapeutic ratio of gemcitabine and radiation. A tumourselective depletion within $30 \mathrm{~min}$ has been reported in mice bearing L1210 ascites after an i.p. injection with $1 \mathrm{mg} / \mathrm{kg}$ CPEC (21). The slower kinetics of CTP depletion observed in our models is probably related to the subcutaneous location of the tumours.

Unfortunately, CPEC was not able to increase the antitumour efficacy of gemcitabine in different doses and applied at different time intervals. In addition, we did not observe any effect on tumour growth delay when CPEC was combined with gemcitabine and radiation in both tumour models. In preliminary experiments, this lack of interaction between CPEC, gemcitabine and radiation was also noted in a model for the acute reaction of the skin of $\mathrm{BN}$ rats bearing $\mathrm{L} 44$ tumours (data not shown). The timing of the combined treatment is very important, because it has been established that pre-incubation with CPEC but not simultaneous application, results in supra-additive effects in combination with cytarabine or gemcitabine in vitro $(18,19,27,32,35,36)$. Enhancement of the efficacy of gemcitabine by hyperthermia also strongly depends on the sequence in vitro as well as in vivo (39). Most studies that investigate the efficacy of combined antitumour treatments use exponentially growing tumour cells $(16,18,19,27,32,35,36)$. The importance of S-phase cells for the efficacy of gemcitabine alone as well as in combination with radiation has been well established in vitro and in vivo $(5,7)$. On the other hand, radiosensitisation by high doses of gemcitabine has been demonstrated for confluent human tumour cells with reduced proliferation rates (8). Solid tumours are known to contain only a limited number of proliferating tumour cells (40), which may be related to so-called cancer stem cells recently also identified in pancreatic cancer $(41,42)$. Therefore, we investigated the efficacy of the combined treatments in two tumour models with quite different growth rates. Yet, we could not demonstrate an effect of CPEC on growth delay after gemcitabine without or with radiation in both tumour models. The profound dose-dependent CTP-depletion by CPEC in both tumour models argues against the hypothesis that CPEC only depleted CTP-levels in cells that were actively cycling. This may be postulated on the observation that retinoic acid reduces human neuroblastoma cell proliferation with a concomitant decrease in the cytotoxicity of CPEC (43). Therefore, we assume that $\mathrm{CPEC}$, gemcitabine and radiation target the same cell populations in the tumour models used in this study.

In conclusion, CPEC has anti-tumour efficacy but it does not enhance the therapeutic ratio of gemcitabine alone or in combination with radiation. Future clinical development of 
CPEC as a modulator of gemcitabine combined with radiation is therefore unlikely.

\section{Acknowledgements}

The authors are very grateful to Geertjan van Tienhoven and Dick Richel for facilitating this study. The authors thank Piter Bosma for assistance with the BxPC-3 model and Bert van Urk and Paulien Kuit for animal care. Arnauld Verschuur, Geertjan van Tienhoven, Jan Paul Medema, Hanneke Wilmink and Caro Koning are acknowledged for their helpful input throughout the study. The Maurits and Anna de Kock foundation is acknowledged for sponsoring laboratory equipment.

\section{References}

1. Yip D, Karapetis C, Strickland A, Steer CB and Goldstein D: Chemotherapy and radiotherapy for inoperable advanced pancreatic cancer. Cochrane Database Syst Rev 3: CD002093, 2006.

2. Burris HA III, Moore MJ, Andersen J, et al: Improvements in survival and clinical benefit with gemcitabine as first-line therapy for patients with advanced pancreas cancer: a randomized trial. J Clin Oncol 15: 2403-2424, 1997

3. Rockwell S and Grindey GB: Effect of 2',2'-difluorodeoxycytidine on the viability and radiosensitivity of EMT6 cells in vitro. Oncol Res 4: 151-155, 1992.

4. Lawrence TS, Chang EY, Hahn TM, Hertel LW and Shewach DS: Radiosensitization of pancreatic cancer cells by 2',2'-difluoro-2'deoxycytidine. Int J Radiat Oncol Biol Phys 34: 867-872, 1996.

5. Latz D, Fleckenstein K, Eble M, Blatter J, Wannenmacher M and Weber KJ: Radiosensitizing potential of gemcitabine ( 2 ', $2^{\prime}$ difluoro-2'-deoxycytidine) within the cell cycle in vitro. Int J Radiat Oncol Biol Phys 41: 875-882, 1998.

6. Mason KA, Milas L, Hunter NR, et al: Maximizing therapeutic gain with gemcitabine and fractionated radiation. Int $\mathrm{J}$ Radiat Oncol Biol Phys 44: 1125-1135, 1999.

7. Milas L, Fujii T, Hunter N, et al: Enhancement of tumor radioresponse in vivo by gemcitabine. Cancer Res 59: 107-114, 1999.

8. Rosier JF, Beauduin M, Bruniaux M, et al: The effect of 2'-2 difluorodeoxycytidine $(\mathrm{dFdC}$, gemcitabine) on radiationinduced cell lethality in two human head and neck squamous carcinoma cell lines differing in intrinsic radiosensitivity. Int J Radiat Biol 75: 245-251, 1999

9. Buchsbaum DJ, Bonner JA, Grizzle WE, et al: Treatment of pancreatic cancer xenografts with Erbitux (IMC-C225) antiEGFR antibody, gemcitabine, and radiation. Int J Radiat Oncol Biol Phys 54: 1180-1193, 2002.

10. Kal HB, El Sharouni SY and Barten-van Rijbroek AD Gemcitabine as a radiosensitizer in undifferentiated tumours. Anticancer Res 26: 139-145, 2006.

11. Crane CH, Antolak JA, Rosen II, et al: Phase I study of concomitant gemcitabine and IMRT for patients with unresectable adenocarcinoma of the pancreatic head. Int $\mathbf{J}$ Gastrointest Cancer 30: 123-132, 2001

12. Wilkowski R, Thoma M, Bruns C, Wagner A and Heinemann V: Chemoradiotherapy with gemcitabine and continuous 5-FU in patients with primary inoperable pancreatic cancer. JOP 7 349-360, 2006.

13. Murphy JD, Adusumilli S, Griffith KA, Ray ME, Zalupski MM, Lawrence TS and Ben-Josef E: Full-dose gemcitabine and concurrent radiotherapy for unresectable pancreatic cancer. Int J Radiat Oncol Biol Phys 68: 801-808, 2007.

14. Hong SP, Park JY, Jeon TJ, et al: Weekly full-dose gemcitabine and single-dose cisplatin with concurrent radiotherapy in patients with locally advanced pancreatic cancer. Br J Cancer 98: 881-887, 2008 .

15. Mornex F and Girard N: Gemcitabine and radiation therapy in non-small cell lung cancer: state of the art. Ann Oncol 17: 1743-1747, 2006.
16. Van Bree $\mathrm{C}$, Rodermond $\mathrm{H}$, Leen $\mathrm{R}$, Medema $\mathrm{J}$ and van Kuilenburg AB: Cyclopentenyl cytosine increases gemcitabine radiosensitisation in human pancreatic cancer cells. Br J Cancer 98: 1226-1233, 2008.

17. Kang GJ, Cooney DA, Moyer JD, Kelley JA, Kim HY, Marquez VE and Johns DG: Cyclopentenylcytosine triphosphate. Formation and inhibition of CTP synthetase. J Biol Chem 264: 713-718, 1989.

18. Verschuur AC, van Gennip AH, Leen R and van Kuilenburg AB: Increased cytotoxicity of 2',2'-difluoro-2'-deoxycytidine in human leukemic cell-lines after a preincubation with cyclopentenyl cytosine. Nucleosides Nucleotides Nucleic Acids 23: 1517-1521, 2004.

19. Bierau J, van Gennip AH, Leen R, Meinsma R, Caron HN and van Kuilenburg AB: Cyclopentenyl cytosine-induced activation of deoxycytidine kinase increases gemcitabine anabolism and cytotoxicity in neuroblastoma. Cancer Chemother Pharmacol 57: 105-113, 2006.

20. Kizaki H, Williams JC, Morris HP and Weber G: Increased cytidine 5'-triphosphate synthetase activity in rat and human tumors. Cancer Res 40: 3921-3927, 1980

21. Moyer JD, Malinowski NM, Treanor SP and Marquez VE: Antitumor activity and biochemical effects of cyclopentenyl cytosine in mice. Cancer Res 46: 3325-3329, 1986.

22. Kal HB, Meijnders PJ, van Berkel AH and van Bekkum DW: Response to chemotherapy of non-small cell bronchial rat tumours growing subcutaneously or in the lung. In Vivo 5: 301-306, 1991.

23. Kal HB, van Berkel AH, Broers JL, et al: Cytokeratins expressed in experimental rat bronchial carcinomas. Int $\mathrm{J}$ Cancer 53: 506-513, 1993.

24. Tan MH, Nowak NJ, Loor R, et al: Characterization of a new primary human pancreatic tumor line. Cancer Invest 4: 15-23, 1986.

25. Schimmel K, Bennink R, De Bruin K, et al: Absence of cardiotoxicity of the experimental cytotoxic drug cyclopentenyl cytosine (CPEC) in rats. Arch Toxicol 79: 268-276, 2005.

26. Zaharko DS, Kelley JA, Tomaszewski JE, Hegedus L and Hartman NR: Cyclopentenyl cytosine: interspecies predictions based on rodent plasma and urine kinetics. Invest New Drugs 9: 9-17, 1991 .

27. Bierau J, van Gennip AH, Leen R, Helleman J, Caron HN and van Kuilenburg AB: Cyclopentenyl cytosine primes SK-N-BE(2)c neuroblastoma cells for cytarabine toxicity. Int J Cancer 20 : 387-392, 2003.

28. Viola JJ, Agbaria R, Walbridge S, et al: In situ cyclopentenyl cytosine infusion for the treatment of experimental brain tumors. Cancer Res 55: 1306-1309, 1995.

29. Schimmel KJ, Gelderblom H and Guchelaar HJ: Cyclopentenyl cytosine (CPEC): an overview of its in vitro and in vivo activity. Curr Cancer Drug Targets 7: 325-334, 2007.

30. Politi PM, Xie F, Dahut W, et al: Phase I clinical trial of continuous infusion cyclopentenyl cytosine. Cancer Chemother Pharmacol 36: 513-523, 1995

31. Verschuur AC, van Gennip AH, Leen R, Meinsma R, Voute PA and van Kuilenburg AB: In vitro inhibition of cytidine triphosphate synthetase activity by cyclopentenyl cytosine in paediatric acute lymphocytic leukaemia. Br J Haematol 110: 161-169, 2000.

32. Schimmel KJ, Nijmeijer BA, van Schie ML, Falkenburg JH and Guchelaar HJ: Limited antitumour-effect associated with toxicity of the experimental cytotoxic drug cyclopentenyl cytosine in NOD/scid mice with acute lymphoblastic leukemia. Leuk Res 31: 1545-1551, 2007.

33. Van Bree $C$ and van Kuilenburg AB: Will cyclopentenyl cytosine (CPEC) ever have a future in the clinic? Leuk Res 32: 201-202, 2008.

34. Grem JL and Allegra CJ: Enhancement of the toxicity and DNA incorporation of arabinosyl-5-azacytosine and 1-beta-Darabinofuranosylcytosine by cyclopentenyl cytosine. Cancer Res 50: 7279-7284, 1990.

35. Verschuur AC, Brinkman J, van Gennip AH, et al: Cyclopentenyl cytosine induces apoptosis and increases cytarabine-induced apoptosis in a T-lymphoblastic leukemic cell-line. Leuk Res 25 : 891-900, 2001.

36. Verschuur AC, van Gennip AH, Leen R, Voûte PA, Brinkman J and van Kuilenburg AB: Cyclopentenyl cytosine increases the phosphorylation and incorporation into DNA of 1-beta-Darabinofuranosyl cytosine in a human T-lymphoblastic cell line. Int J Cancer 98: 616-623, 2002. 
37. Grem JL, Plowman J, Rubinstein L, Hawkins MJ and Harrison SD Jr: Modulation of cytosine arabinoside toxicity by 3-deazauridine in a murine leukemia model. Leuk Res 15: 229-236, 1991.

38. Duxbury MS, Ito $\mathrm{H}$, Zinner MJ, Ashley SW and Whang EE: RNA interference targeting the M2 subunit of ribonucleotide reductase enhances pancreatic adenocarcinoma chemosensitivity to gemcitabine. Oncogene 23: 1539-1548, 2004

39. Van Bree C, Beumer C, Rodermond HM, Haveman J and Bakker PJ: Effectiveness of 2',2'difluorodeoxycytidine (Gemcitabine) combined with hyperthermia in rat R-1 rhabdomyosarcoma in vitro and in vivo. Int J Hyperthermia 15: 549-556, 1999

40. Barendsen GW, van Bree C and Franken NA: Importance of cell proliferative state and potentially lethal damage repair on radiation effectiveness: implications for combined tumor treatments. Int J Oncol 19: 247-256, 2001
41. Li C, Heidt DG, Dalerba P, et al: Identification of pancreatic cancer stem cells. Cancer Res 67: 1030-1037, 2007.

42. Hermann PC, Huber SL, Herrler T, et al: Distinct populations of cancer stem cells determine tumor growth and metastatic activity in human pancreatic cancer. Cell Stem Cell 1: 313-323, 2007.

43. Bierau J, van Gennip AH, Leen R, Caron $\mathrm{HN}$ and van Kuilenburg AB: Retinoic acid reduces the cytotoxicity of cyclopentenyl cytosine in neuroblastoma cells. FEBS Lett 11: 229-233, 2002. 